\title{
O INCONSCIENTE FREUDIANO ENTRE LOU-ANDRÉAS SALOMÉ E VICTOR TAUSK ${ }^{*}$
}

Luiz Eduardo Prado de Oliveira

\author{
Diretor de \\ Pesquisas na \\ École Doctoral \\ e Recherches \\ en sychanalyse, \\ Universidade \\ de Paris 7 \\ Denis Diderot; \\ professor de \\ psicopatologia \\ clínica e \\ psicanálise na \\ Universidade \\ da Bretanha \\ Ocidental; \\ doutor em \\ psicopatologia \\ e psicanálise \\ Tradução \\ Marcia Herzog
}

RESUMO: O presente artigo trata de "O inconsciente", texto metapsicológico escrito por Freud em 1915. Viso, aqui, indicar as diferentes abordagens e fontes que o influenciaram na elaboração deste conceito, assim como os impasses que precisou resolver e a importância da transferência no âmbito da clínica e da teoria. Discutirei cada um dos sete capítulos do referido trabalho.

Palavras-chave: Inconsciente, psicanálise, transferência.

ABSTRACT: The Freudian unconscious between Lou-Andréas Salomé and Victor Tausk. The present article intends to tackle "The Unconscious", metapsychological text written by Freud in 1915. I wish to indicate here the different approaches and sources that have influenced the elaboration of this concept, as well as the barriers that it needed to overcome and the importance of transference to the author, in the clinical and theoretical work. I will discuss each one of the seven chapters of the referred work.

Keywords: Unconscious, psychoanalysis, transference.

Em $1^{\circ}$ de abril de 1915, Freud escreveu a Lou Andreas-Salomé:

“Os próximos números do Journal irão conter um tipo de síntese psicológica de várias de minhas idéias sobre três temas: o instinto e suas vicissitudes, a repressão e o inconsciente - incompleto, como tudo o que faço, porém não sem algo de novo. O artigo sobre inconsciente em particular conterá uma nova definição do termo, que é de fato o equivalente a uma agnostização." (ANDREAS-SALOMÉ, 1912-13, p.38) ${ }^{1}$

\footnotetext{
*Este artigo é uma versão ampliada da que foi publicada em Perelberg (2005).

${ }^{1}$ A tradução desta carta em francês introduz o termo 'agnostização', que não aparece na tradução inglesa, a qual por sua vez é redundante. Importaria verificar o original alemão e precisar se a tradução em português é feita a partir do alemão ou do inglês.
} 
Este neologismo, baseado no alemão Agnoszierung, sugere um caráter religioso ou sacro, marcado por uma forte crença, e ligado, de antemão, ao inconsciente. Freud pretende propor uma nova definição, desconhecida. Um estudo perspicaz de seu texto nos permite concluir de que forma sua definição foi inovadora, não tanto em consideração a sua tese sobre o sujeito em seu tempo, mas principalmente considerando as próprias abordagens freudianas.

Os editores da Edição standard, por exemplo, escrevem, na introdução ao texto de 1915 sobre o inconsciente:

“Desde o início, e em seu ambiente mais próximo, não pode ter havido grande resistência a essa idéia. Seus professores diretos — Meynert, por exemplo —, na medida que se interessavam pela psicologia, orientavam-se principalmente pelos conceitos de J. F. Herbart (1776-1841), e parece que um livro de texto contendo os princípios herbartianos era usado na escola secundária freqüentada por Freud." (FREUD, 1915c/ 1974, p.186)

Estes pontos de vista, por mais interessantes que sejam, não cobrem todo o campo das contribuições que podem ter influenciado Freud, em dois sentidos: no sentido de contribuições mais recentes, contemporâneas à obra de Freud, e também como contribuições mais antigas, mais conhecidas e divulgadas do que as próprias idéias de Meynert ou de Herbart.

\section{DIFERENTES ABORDAGENS E FONTES PARA}

\section{A ELABORAÇÃO DO INCONSCIENTE}

De fato, Edward von Hartmann (1842-1906) publica, em 1869, uma Philosophie des Unbewussten, que recebe grande aclamação pública e o torna famoso da noite para o dia. Neste livro, Hartmann faz homenagem a seus antecessores: Schelling, Hegel e Schopenhauer. Iniciando com uma análise dos fenômenos orgânicos, estabelece uma oposição entre instinto 'repulsivo', como o medo da morte ou a aversão, por um lado, e instinto 'empático', como o amor materno ou o amor sexual, por outro. Moral, estética e misticismo estão enraizados nesta oposição, tanto quanto o conceito de sublimação que, mesmo não sendo estudada como tal por Hartmann, está presente na Alemanha desde Kant, cuja sombra paira sobre as teses de Freud (PRADO DE OLIVEIRA, 1998, p. 117-26). Para Hartmann, o inconsciente pertence à metafísica e é atemporal. Freud guarda esta última característica, e o transforma em conceito metapsicológico. Até a oposição entre dois grupos fundamentais de 'instinto' e sua resolução na morte, parece ter marcado a psicanálise. ${ }^{2}$ De fato, considerando a contribuição de Hartmann, é fácil

\footnotetext{
2 Para uma argüição dos pensamentos de Hartmann e Freud, cf. Whyte (1971) e Brès (1985).
} 
conceber que Freud tenha desejado um Agnoszierung da noção de inconsciente, desfazendo-se de qualquer conotação religiosa.

Com relação aos contemporâneos de Freud que podem ter influenciado seu pensamento e estimulado seu esforço para teorizar o inconsciente, temos, claramente, Bleuler, que em 1906 publicou Unbewusstes und Assoziation como uma contribuição aos estudos de Jung sobre livres associações, o qual aparece em seu Assoziationsstudien. Hirschman relembra sua própria contribuição Uma apresentação geral das teorias de Freud (Propaganda entre médicos), na reunião da Sociedade Psicanalítica de Viena, em 21 de abril de 1909, quando declara:

“As dificuldades para entender as psiconeuroses estão enraizadas no conceito do inconsciente e na sexualidade infantil, que deve ser substanciada em termos de uma ciência puramente empírica. Seria necessário tratarmos longamente do conceito de inconsciente, e entrar em detalhes sobre seu papel virulento [patogênico]. Ao mesmo tempo, teríamos que transmitir alguns conhecimentos necessários sobre os sonhos, piadas e a vida cotidiana. Para terminar, teríamos que mencionar brevemente a análise, como único método através do qual se pode aprender algo sobre o inconsciente. Sobre o inconsciente propriamente dito, é preciso dizer: antes de tudo, o quanto contém em termos de material reprimido (Bleuler: Unbewusstes und Assoziation); em segundo lugar, que não podemos entender o inconsciente sem (conhecer) o fenômeno do hipnotismo, da sugestão e da dupla consciência." (NUNBERG e FEDERN, 1908-10, p.206 da edição francesa).

De fato, o interesse de Freud pelo inconsciente está presente desde o começo de sua pesquisa psicanalítica. Desde 1895, quando reflete a respeito da cura de Emmy von N., Freud, escreve em uma nota:

"Seu assombro, na noite anterior, quanto ao fato de haver decorrido tanto tempo desde que tivera câimbras no pescoço era assim um pressentimento de um estado que se aproximava, que já estava em elaboração na ocasião, e que foi percebido inconscientemente [cf. p.93, nota 1]. Essa curiosa espécie de pressentimento ocorria regularmente no caso já mencionado [p.113] de Frau Cäcilie M. Se, por exemplo, enquanto gozava de melhor saúde, me dissesse: 'Faz muito tempo que não me tenho assustado com feiticeiras à noite', ou, 'estou muito satisfeita por não ter dores nos olhos há tanto tempo’, eu podia estar certo de que na noite seguinte uma grave investida de seu medo de bruxas daria trabalho adicional à sua enfermeira, ou que uma crise de dores nos olhos estava prestes a começar. Em cada uma das ocasiões o que já se achava presente como um produto acabado no inconsciente, estava começando a revelar-se indistintamente. Esta idéia, que surgiu como uma súbita noção, foi elaborada pela insuspeita consciência 'oficial' (para empregarmos 
a expressão de Charcot) numa sensação de satisfação, que rápida e invariavelmente mostrava-se injustificada. Frau Cäcilie, mulher muito inteligente, a quem sou grato pela grande ajuda recebida quanto à minha compreensão dos sintomas histéricos, me ressaltou que fatos dessa natureza podem ter dado margem a superstições sobre o perigo de vangloriar-se ou de prever males. Não devemos, por um lado, alardear nossa felicidade, nem, por outro, falar do pior, senão ele acontecerá.” (FREUD, 1893-95/1974, p.121)

A teoria do inconsciente tem então, com toda a certeza, fundamentos clínicos. Se nesta anotação é a primeira vez que este termo aparece no trabalho de Freud, é importante indicar que aparece seguindo seus próprios questionamentos em suas anotações anteriores, sem dúvida uma das anotações mais longas na história da literatura. Freud retoma integralmente este questionamento em seu artigo de 1915 (FREUD, 1915c/1974) não só uma, mas diversas vezes, como podemos ver. Trata-se da questão da dupla inscrição ou do duplo registro das representações e dos afetos, bem como do destino destas inscrições ou registros. Freud sublinha o Spaltung da consciência, a constituição das representações préconscientes e sua passagem de um registro a outro. O conceito de repressão ainda não foi elaborado, mas Freud sublinha as 'associações falsas', que percorrem certas representações da consciência (BREUER e FREUD, 1893-95/1974).

Parece-me que os editores da Edição standard não dão a devida atenção à base essencialmente clínica, e até auto-analítica, do conceito de inconsciente, mesmo que indiquem:

"Contudo, deve-se esclarecer de imediato que o interesse de Freud por essa suposição jamais foi de natureza filosófica — embora, sem dúvida, problemas filosóficos se encontrassem inevitavelmente próximos. Seu interesse era prático. Achava que, sem fazer essa suposição, era incapaz de explicar ou mesmo descrever a grande variedade de fenômenos com que se defrontava. Por outro lado, procedendo assim, encontrou o caminho aberto para uma região imensamente fértil em novos conhecimentos." (FREUD, 1915c/1974, p.186)

O fato é que os editores da referida edição não mencionam sequer uma única destas ocasiões 'práticas' nas quais o conceito de inconsciente tenha sido tão útil. Pelo contrário, o tratam amplamente no nível teórico. Podemos segui-los, mas enriquecidos pelos avanços teóricos e clínicos feitos desde então, o que significa um retorno às considerações relativas à transferência e ao desejo do analista, visando a melhor compreensão global.

Por exemplo, esses editores escrevem: 
"Na verdade, toda a base da teoria da repressão na histeria, e a do método catártico de tratamento, exigiam uma explicação psicológica, e só através dos mais penosos esforços foram elas explicadas neurologicamente na Parte II do 'Projeto'. Alguns anos depois, em $A$ interpretação dos sonhos (1900a), uma estranha transformação ocorre: não só a explicação neurológica da psicologia desaparece completamente, mas também grande parte do que Freud havia escrito no 'Projeto' em termos do sistema nervoso torna-se agora válido, e muito mais inteligível, ao ser traduzido em termos mentais." (FREUD, 1915c/1974, p.188)

E eles concluem (o que quero sublinhar): “O inconsciente foi estabelecido de uma vez por todas" (FREUD, 1915c/1974:164).

A principal marca de posição teórica parece bem sedimentada, mas algumas teses são insatisfatórias. Supor que o inconsciente foi estabelecido de uma vez por todas parece descartar qualquer surpresa e, como tal, qualquer confusão, bem como qualquer medo, na tarefa de redescobri-lo. E isso é realmente um problema. Por outro lado, criar um caminho singular em direção ao inconsciente exige uma disposição permanente para manter sempre aberta e renovada a experiência que se tem dele. Assim, não aparece em Entwurf Einer Psycologie, de 1895 - a cujo título diferentes tradutores com freqüência adicionam o termo ‘científico' - um modelo quase geométrico do aparato do pensamento, ao qual o inconsciente pertence, e sim mais cedo, em uma carta a Fliess, quando Freud tenta entender a melancolia. Ele se questiona: "Como pode ser possível que a anestesia tenha um papel na melancolia?" (FREUD \& FLIESS, 1985 [1887-1904], p.100-2). E para responder a esta pergunta, Freud faz um primeiro rascunho do aparato da alma, no qual aparecem termos como 'fronteira do ego', 'mundo externo', 'objeto sexual', 'tensão sexual', 'grupo psíquico', etc. Este diagrama, em seu caráter geral, é repetido e simplificado para explicar a melancolia e, particularmente, a mania.

De fato, em 27 de abril de 1895, Freud escreve a Fliess que está imerso em seu projeto de 'Psicologia para neurologistas' e, no mesmo ano, em 25 de maio, explica sua incapacidade de abandonar este trabalho:

"Contudo, a principal razão foi esta: um homem como eu, não pode viver sem um tema favorito, sem uma paixão consumidora, sem — nas próprias palavras de Schiller — um tirano. Achei um. A seu serviço não há limites. É a psicologia, que sempre foi minha meta, que acena de longe, e agora, ao ter me deparado com o problema da neurose, tornou-se bem mais próxima. Estou atormentado por dois objetivos: examinar que forma a teoria do funcionamento mental adquire uma vez que se introduzam considerações quantitativas, um tipo de economia das forças nervosas; e, em segundo lugar, extrair da psicopatologia um ganho para a psicologia normal. $\mathrm{Na}$ 
verdade, uma concepção geral satisfatória dos distúrbios neuropsicóticos é impossível se não se pode ligá-los com suposições claras sobre o processo mental normal.” (FREUD apud MASSON, 1985, p.129) ${ }^{3}$

O projeto de 'Psicologia para neurologistas' é apenas superficialmente inspirado no modelo geométrico que aparece na carta a Fliess, mesmo que o inconsciente reapareça de modo claro. É também verdadeiramente um projeto psicológico, mesmo que a neurologia funcione como uma metáfora, qualquer verdadeira preocupação neurológica estando realmente longe da mente de Freud naquele momento. Por fim, mas não menos importante, neste texto, o inconsciente é claramente ligado aos sonhos (FREUD, 1966[1895]/1974, p.341-3).

O melhor exemplo conclusivo das reflexões de Freud neste momento aparece em uma de suas cartas a Fliess no final do ano seguinte, mais explícita do que qualquer outra coisa que tenha escrito antes (FREUD \& FLIESS, 1985 [18871904], p.207-15). Esta carta é, de fato, o verdadeiro rascunho do conhecido Capítulo 7 de $A$ interpretação dos sonhos. Atesta, então, o todo de seu modelo topográfico do aparato psíquico, e seu projeto psicológico é evidentemente mais claro.

Em $A$ interpretação dos sonhos (1900/1975), Freud mais uma vez trabalha o seu modelo, visando livrar-se de qualquer referência aos períodos de Fliess, em relação aos quais mantivera fidelidade. É neste sentido que tal trabalho apresenta uma versão finalizada do aspecto topográfico de sua metapsicologia e, portanto, da situação topográfica do inconsciente. A percepção aparece em um extremo do aparato do pensamento; a acumulação de traços mnemônicos, neste extremo, é a fonte do inconsciente, e daí alguns destes traços tornarem-se pré-conscientes no outro extremo do aparato, pouco antes da atividade motora. O que se origina no mundo externo, o que primeiramente veio dele como percepção, a ele retorna, como atividade, como ato, como ação (FREUD, 1900-1/1975, p.537-41). Além disso, alguns elementos da percepção podem se inscrever diretamente no registro pré-consciente.

As cartas a Fliess, assim como o projeto para uma psicologia, estavam ambos interligados com a transferência e preocupações clínicas. Conhece-se bem a transferência de Freud em relação a Fliess. A interpretação dos sonhos (1900-1/1975) tem origem no luto de Freud por seu pai, mas também com o fim da amizade com Fliess. Este livro é o mais importante esforço já alcançado em auto-análise.

\footnotetext{
${ }^{3}$ Passagem censurada em todas as outras edições da correspondência entre Freud e Fliess, particularmente interessante pelo fato de que, contrariamente ao que muitos autores pretendem, a partir de Lacan, Freud sempre reivindica a psicologia e ataca a psiquiatria. Acusar a psicologia em nome da psiquiatria é um passo propriamente francês e, de toda forma, ipeísta.
} 


\section{O ARTIGO SOBRE 0 INCONSCIENTE}

1912 é um ano em que Freud publicou vários artigos importantes: 'Totem e tabu', com certeza, mas também 'Dinâmica da transferência', 'Sobre a tendência universal à depreciação na esfera do amor (Contribuições à psicologia do amor)', 'Recomendações aos médicos que exercem a psicanálise', 'Tipos de desencadeamento da neurose', 'Contribuições a um debate sobre a masturbação' - este último sendo o mais discutido na Sociedade Psicanalítica de Viena, quando nove reuniões foram dedicadas à questão, abordando-a de forma original, coisa que o liga ao segredo e à vida institucional - e, finalmente 'Uma nota sobre o inconsciente na psicanálise’. De vários pontos de vista o artigo de 1915, “O inconsciente", é uma versão revisada deste último.

No mesmo ano, houve uma ruptura entre Freud e Stekel, justo quando Freud acabara de romper com Adler e começava a se separar de Jung. Mais uma vez, seus pensamentos sobre o inconsciente estavam ligados ao luto. Em 2 de janeiro de 1912, ele escreveu a Abraham: "Para mim mesmo, não tenho grandes expectativas; tempos sombrios estão por vir, e reconhecimento provavelmente só virá para a próxima geração” (FREUD \& ABRAHAM, 1907-25, p.145). Pouco depois de romper com seu primeiro aluno e paciente propriamente psicanalítico, Stekel, ainda no mesmo ano, Freud criou o Internationale Zeitschrif für Ärztliche Psychoanalyse. Tantos manuscritos, tantas iniciativas, tudo isso foi considerado como um 'período negro’!

Neste mesmo ano, 1912, diretamente em inglês, respondendo à demanda da Society for Psychical Research, de Londres, Freud escreve um curto texto intitulado 'Uma nota sobre o inconsciente na psicanálise', que já apresentava a essência do que mais tarde desenvolveria em 1915 e, em essência, propunha uma abordagem do aparato do pensamento e do inconsciente que levava em consideração seus aspectos topológicos, dinâmicos e descritivos. Os editores da Edição standard escrevem:

"O presente relato é mais elaborado e claro que o muito mais sucinto fornecido na Seção II do artigo maior. Neste, apenas dois usos são diferenciados, o ‘descritivo’ e o 'sistemático', e nenhuma distinção clara parece ser feita entre este último e o 'dinâmico' - termo que, no presente artigo, é aplicado ao inconsciente reprimido." (FREUD, 1912c/1974, p.325)

E, de fato, têm razão! O texto curto, efetivamente claro, começa com uma proposta:

“Ora, permitam-nos chamar de 'consciente' a concepção que está presente em nossa consciência e da qual nos damos conta, e que este seja o único significado do termo 
'consciente'. Quanto às concepções latentes, se temos qualquer razão para supor que existam na mente - como tínhamos, no caso da memória - que sejam designadas pelo termo 'inconsciente'." (FREUD, 1912c/1974, p.328)

O que lhe permite insistir nesta diferença, fora a memória e as associações, é a sugestão pós-hipnótica e, basicamente, a experiência de Bernheim na França, que Freud descreve (1912c/1974). Esta experiência lhe permite diferenciar uma abordagem dinâmica do inconsciente, que reconhece a existência do pensamento mantido longe do consciente, apesar de sua intensidade e de sua atividade. Desta forma, além dos estados mentais consciente e inconsciente, Freud reafirma a existência de estados pré-conscientes, cuja existência já havia sido proposta em 'A interpretação dos sonhos' (1900-1/1975).

Também traz de volta sua tese de 1901, segundo a qual a atividade psíquica é inconsciente no começo e, em seguida, ou assim permanece ou segue seu caminho em direção ao consciente de acordo com as resistências encontradas, ou não, vindas de representações distintas do psíquico. Freud chega a comparar a relação entre o inconsciente e o consciente com a relação entre positivo e negativo quando se revela uma foto. Seria interessante apontar as várias articulações feitas por Freud entre essas duas noções, como quando afirma que a neurose é o 'negativo' da perversão, concebida como ‘positivo' (FREUD \& FLIESS, 1887-1904, p.227). ${ }^{4}$ Além disso, o inconsciente não apenas se torna consciente, mas um movimento inverso muitas vezes ocorre, quando elementos que pertencem ao consciente retornam ao domínio do inconsciente como os pensamentos latentes dos sonhos.

Ao final deste texto, Freud faz duas declarações importantes: a primeira delas questiona as leis do pensamento inconsciente, no quanto diferem das do pensamento consciente; a segunda declaração afirma a natureza independente do sistema inconsciente; e propõe designá-lo utilizando três letras — 'Ics' ou, em alemão, 'Ubw'. Esta proposta já havia sido apresentada em uma carta a Fliess no final de 1896.

O artigo sobre o inconsciente é dividido em sete capítulos, compreendendo: a justificativa para tal conceito, os vários sentidos do termo e o ponto de vista topográfico, as emoções inconscientes, a topografia e dinâmica da repressão, as características específicas do sistema Ics, a comunicação entre os dois

\footnotetext{
${ }^{4}$ Por exemplo, sua carta a Fliess, de 24 de janeiro de 1897: “Em minha mente está-se formando a idéia de que, nas perversões, das quais a histeria é o negativo..." (v. I, p.329). E novamente: "Portanto, os sintomas se formam, em parte, às expensas da sexualidade anormal; a neurose é, por assim dizer, o negativo da perversão" (FREUD, 1905/1974, p.168). Pelo que Freud escreve sobre a relação entre o inconsciente e o consciente, deveríamos esperar um conceito que se encaminharia de forma inversa.
} 
sistemas, isto é, o inconsciente e o consciente, e, finalmente, a avaliação do inconsciente. Estes capítulos são de importância desigual e apresentam uma tese previamente desenvolvida de forma também desigual. O entusiasmo mostrado por Freud em sua carta de $1^{\circ}$ de abril a Lou Andreas-Salomé é altamente questionável. A ‘agnostização’ do inconsciente já havia ocorrido bem antes de seu novo texto. Também é surpreendente como Freud se arranja para nunca citar nenhum de seus antecessores ou contemporâneos que lidavam com o mesmo conceito, nem mesmo para rejeitá-los. Mas ainda assim este texto encerra uma importância considerável: representa um grande esforço em responder a uma série de questões que aparecem com freqüência nos trabalhos de Freud: pode uma mesma coisa existir simultaneamente em vários lugares distintos e se manifestar de maneiras diferentes? E também: podem duas ou mais coisas diferentes ocupar simultaneamente um só lugar e se manifestar de modos similares? A resposta a estas perguntas é sempre positiva. O conceito de sobredeterminação ou de múltiplas determinações é a base para esta resposta e traz à tona todas as suas ramificações. Este conceito, um dos mais revolucionários no pensamento de Freud, é ainda bastante inexplorado, não apenas na psicanálise, mas em geral.

Assim sendo, a introdução a este texto de 1915 começa com uma comparação entre o reprimido e o inconsciente. Imediatamente, amplia-se o domínio do inconsciente que não está restrito ao reprimido, o que traz uma nova questão: 'como devemos chegar a um conhecimento do inconsciente?' (FREUD, 1915c/ 1974, p.191). Existem várias respostas. A primeira delas: há uma tradução permanente em progresso entre o inconsciente e o consciente. Nunca é demais insistir acerca da grande importância da noção de tradução no trabalho de Freud.

Uma segunda resposta para a atual questão é oferecida neste mesmo capítulo, uma questão que, em essência, está dividida em duas partes:

“A consciência torna cada um de nós consciente apenas de nossos próprios estados mentais; que também outras pessoas possuam uma consciência é uma dedução que inferimos por analogia de suas declarações e ações observáveis, a fim de que sua conduta fique inteligível para nós... Essa inferência (ou essa identificação) foi anteriormente estendida pelo ego a outros seres humanos, a animais, a plantas, a objetos inanimados e ao mundo em geral... A psicanálise exige apenas que também apliquemos esse processo de inferência a nós mesmos... Se o fizermos, deveremos dizer: todos os atos e manifestações que noto em mim mesmo, e que não sei como ligar ao resto de minha vida mental, devem ser julgados como se pertencessem a outrem; devem ser explicados por uma vida mental atribuída a essa outra pessoa." (FREUD, 1915c/1974, p.195) 
E ainda: "Na psicanálise, não temos outra opção senão afirmar que os processos mentais são inconscientes em si mesmos, e assemelhar sua percepção por meio da consciência à percepção do mundo externo por meio dos órgãos sensoriais" (FREUD, 1915c/1974, p.197).

Trata-se, de fato, de duas respostas diferentes: a primeira aborda a importância dos processos analógicos, e a segunda aborda a possibilidade de que sejam aplicados às verdadeiras relações entre consciente e inconsciente. Mas desde o começo do capítulo o leitor deve entender que, no que diz respeito à psicanálise, fatos importantes a serem observados são essencialmente as parapraxias, os sonhos, os sintomas e as compulsões, bem como "idéias que não sabemos de onde vêm e entram na nossa cabeça, e conclusões intelectuais que nos chegam não sabemos como" (1915c/1974, p.192).

Assim sendo, o capítulo sobre a justificação do conceito de inconsciente, muito mais do que simplesmente apresentar uma lista de fatos que permite o estabelecimento de uma hipótese, também introduz uma metodologia para observar estes fatos, isto é, traduções, analogias e a percepção de um próprio eu como elemento do mundo externo.

Quero frisar a analogia da percepção endopsíquica e a percepção do resto do mundo. Ela se sustenta, também, em importantes dados para o entendimento das técnicas psicanalíticas contemporâneas. Freud declara: "Hoje em dia, nosso julgamento crítico já se põe em dúvida quanto à questão da existência de consciência nos animais; recusamo-nos a admiti-la nas plantas e encaramos como misticismo a suposição de sua existência nas coisas inanimadas" (FREUD, 1915c/1974, p.195). Mas o problema não mais parece pertinente. Tal abordagem mística parece de certa forma ligada ao reducionismo. Hoje em dia, com base no conhecimento psicanalítico da psicose, longe da característica científica dos tempos de Freud, parece que aquelas crenças correspondem aos primeiros passos de reconhecimento de si próprio como ser humano, depois de se reconhecer como pertencente ao mundo e, portanto, ao inanimado e ao reino vegetal. Nossas crenças têm raízes em antigas identificações, como já o mostra Ferenczi. ${ }^{5}$

O segundo capítulo trata dos vários significados do conceito de inconsciente e da abordagem topográfica. E parece, hoje em dia, ser realmente um capítulo problemático. Como os editores ingleses da edição padrão têm apontado, este capítulo é mais pobre do que o artigo de 1912c, pois agora 'apenas dois usos são diferenciados, o ‘descritivo’ e o ‘sistemático’, e nenhuma distinção clara parece ser feita entre este último e o ‘dinâmico’ (FREUD, 1912c/1974, p.325). Mas

\footnotetext{
${ }^{5}$ Ferenczi, S. “Le développement du sens de la réalité et ses stades” EFuvres complètes, t. II, trad. J. Dupont et M. Wiliker, Payot, Paris, 1970, p.51-65).
} 
também porque a articulação entre o consciente, o pré-consciente e o inconsciente já foi bem estabelecida e bem desenvolvida desde muito tempo.

Se este capítulo ainda desperta interesse, isto se deve às suas propostas clínicas, que aparecem em um de seus últimos parágrafos. Freud escreve:

“Se comunicamos a um paciente uma idéia que reprimiu em certa ocasião, mas que conseguimos descobrir, o fato de lhe dizermos isto não provoca, de início, qualquer mudança em sua condição mental. Acima de tudo, não remove a repressão nem anula seus efeitos, como talvez se pudesse esperar do fato de a idéia previamente inconsciente ter-se tornado agora consciente. Pelo contrário, tudo o que de início conseguiremos será uma nova rejeição da idéia reprimida. No entanto, agora, o paciente tem de modo concreto a mesma idéia, sob duas formas, em diferentes lugares de seu mecanismo mental: primeiro, possui a lembrança consciente do traço auditivo da idéia, transmitido no que lhe dissemos; segundo, também possui - como temos certeza - a lembrança inconsciente de sua experiência - em sua forma primitiva. Realmente, não há supressão de repressão até que a idéia consciente, após as resistências terem sido vencidas, entre em ligação com o traço de lembrança inconsciente. Só quando este último se torna consciente é que se alcança o êxito. Numa consideração superficial, isso pareceria revelar que as idéias conscientes e inconscientes constituem registros distintos, topograficamente separados, de mesmo teor. Mas basta uma rápida reflexão para mostrar que a identidade entre a informação dada ao paciente e sua lembrança reprimida é apenas aparente. Ouvir algo e experimentar algo são, em sua natureza psicológica, duas coisas bem diferentes, ainda que o conteúdo de ambas seja o mesmo." (FREUD, 1915c/1974, p.202)

As observações sobre a diferença e a similitude entre a experiência que um indivíduo tenha vivido e que tenha escutado são antigas. Aparecem primeiramente em 1897, quando tais ligações são ainda mais desenvolvidas do que quando aparecem em 1915. Em 1897, Freud as menciona duas vezes: primeiro em uma carta de 16 de maio a Fliess, quando afirma: "As fantasias derivam, como na histeria, do que se tem escutado e entendido subseqüentemente." Nesta afirmação pode-se ler que existe uma distância temporal entre a fonte da Nächträglichkeit e a própria Nächträglich e, no Manuscrito M, é incluída em uma carta ao seu amigo, alguns dias mais tarde, a seguinte formulação: “Fantasias surgem de uma combinação inconsciente de coisas vividas e escutadas, de acordo com certas tendências” (FREUD \& FLIESS, 1895 [1887-1904], p.243 e 247).

A ligação entre o que foi escutado e o que foi vivido se encontra bastante reduzida em 1915. Agora, o que foi escutado se torna apenas o que o paciente escutou do analista. Freud não esclarece que esses são acrescentados àqueles que ele havia escutado em outros tempos, em seu próprio ‘país estrangeiro' da infância. 
Esta nova definição parece ser a base de um método em que a única preocupação do analista se torna a interpretação da transferência, excluindo qualquer esforço de reconstrução com base nas lembranças ou em novas associações.

A sabedoria clínica de Freud levanta a questão da existência de emoções inconscientes no terceiro capítulo e encara a complexidade das possíveis respostas. É impossível, de fato, falar de 'sentimentos inconscientes', tanto quanto é impossível falar de pulsões inconscientes, dado o fato de que apenas as representações da pulsão vêm a ser inscritas no inconsciente. As próprias pulsões pertencem ao reino biológico. Todavia, como a linguagem comum do psicanalista trata freqüentemente da noção dos sentimentos inconscientes, é de boa recomendação tentar pesquisar a correspondência entre este modo de falar e a realidade que de fato procuram descrever. Então, de fato, existe certo paralelismo entre pulsões e emoções, pois estas têm bases biológicas (o coração acelerado, suor, etc.). Por outro lado, no sistema consciente, os sentimentos têm suas próprias representações. Os próprios afetos podem corresponder em grande maioria a uma tradução da pulsão em algo acessível para a consciência:

"Podemos dizer que, enquanto o sistema Cs controla a afetividade e a motilidade, a condição mental da pessoa em questão é considerada como normal. [...] Enquanto o controle do Cs sobre a motilidade voluntária se acha firmemente enraizado, suporta regularmente a investida da neurose e só cessa na psicose, o controle do Cs sobre o desenvolvimento dos afetos é menos seguro.” (FREUD, 1915c/1974, p.205)

Esta observação interessante é esclarecida em nota:

"A afetividade manifesta-se essencialmente na descarga motora (secretora e vasomotora) resultante de uma alteração (interna) do próprio corpo do indivíduo, sem referência ao mundo externo; a motilidade, em ações que se destinam a efetuar modificações no mundo externo.” (FREUD, 1915c/1974, p.205, nota 2)

Continua sendo objeto de discussão saber se os afetos não são ligados a eventos externos.

Este terceiro capítulo prepara o seguinte, bastante rico em relação a reflexões clínicas psicanalíticas. Sustenta-se na repressão, um conceito estabelecido, e seu título é ‘Topografia e dinâmica da repressão'. Repressão, afirma Freud, corresponde a uma "retirada do investimento; mas a questão é: em que sistema ocorre a retirada e a que sistema pertence o investimento retirado?" (FREUD, 1915c/ 1974, p.207).

Quando aborda essas questões, Freud cita muito outro de seus artigos que também aparece em 'Artigos em metapsicologia', cujo título é 'Repressão'. 
É pertinente questionar a verdadeira necessidade de introduzir em um estudo sobre o inconsciente toda essa seção dedicada à repressão, quando o autor já apresentara, algumas páginas antes, um estudo completo sobre a questão.

Também os editores da edição standard parecem negligenciar dois aspectos importantes do trabalho da teoria freudiana sobre estes assuntos, tanto na introdução do artigo sobre a repressão quanto na introdução ao texto do inconsciente. A repressão, afirma aqui Freud, é dividida em dois momentos distintos: o primeiro, uma repressão primária, quando a divisão da pulsão ocorre, proibindo o acesso ao consciente e à representação desta pulsão. Nesta fase ocorre a fixação (em itálico no artigo de Freud). “A segunda fase da repressão, a repressão propriamente dita, afeta os derivados mentais do representante reprimido, ou sucessões de pensamento que, originando-se em outra parte, tenham entrado em ligação associativa com ele" (FREUD, 1915b/1974, p.171).

Em ambos os artigos, um deles o quarto capítulo sobre o inconsciente e o outro, no próprio texto da repressão, os mesmos exemplos clínicos são descritos: a ação da repressão na ansiedade histérica, na conversão histérica e na neurose obsessiva.

Os referidos editores, quando introduzem o artigo da repressão, reduzem sua ação à neurose de ansiedade, em que, de acordo com Freud, a repressão é similar às defesas. E, sobretudo, tais editores, em sua introdução ao artigo sobre o inconsciente, também introduzem a confusão entre inconsciente e metapsicologia (FREUD, 1915c/1974, p.165-7, 185-9). Ora, a metapsicologia não se reduz ao inconsciente.

Todavia, a mais completa teoria da repressão de Freud, de um ponto de vista clínico, é apresentada em seu texto sobre o caso Schreber, de 1911. O autor aí enfoca a questão e a amadurece após a troca de cartas com Jung e Ferenczi. A primeira definição freudiana do que é a metapsicologia aparece em cartas trocadas com Fliess e Abraham sobre a melancolia (PRADO DE OLIVEIRA, 1997). Paranóia e melancolia são assuntos que tornam imperioso criar novos métodos de pensamento, ou seja, a teoria psicanalítica e a abordagem metapsicológica da mente, na qual a repressão tem papel importante. A metapsicologia não deve ser misturada com suas aplicações, inconsciente ou consciente, sintomas ou fantasias. Freud ressalta isto neste quarto capítulo, quase nos mesmos termos utilizados em suas cartas a Abraham: "Proponho que, quando tivermos conseguido descrever um processo psíquico em seus aspectos dinâmico, topográfico e econômico, passemos a nos referir a isso como uma apresentação metapsicológica" (FREUD, 1915c/1974, p.208).

De maneira exata: 'isso’ significa a descrição dos modos de trabalho da mente e não da própria mente ou do próprio trabalho. Um procedimento da mente ou uma instância da mente, propriamente, não são nunca 'metapsicológicos'. Apenas o nosso modo de pensar sobre eles ou como se descreve sua existência pode vir a sê-lo. 
É interessante comparar exemplos clínicos que aparecem no artigo sobre a repressão e a forma como Freud os trata nesta parte de seu texto sobre o inconsciente. Depois de comparar repressão com as três grandes neuroses da época histeria de ansiedade, histeria de conversão e neurose obsessiva — o artigo sobre o inconsciente simplesmente descreve a repressão na neurose de ansiedade e a compara às outras duas formas de perturbações da mente.

Freud, no quinto capítulo, volta ao estudo do inconsciente propriamente dito. Define então as características especiais do sistema Ics. Trata-se de uma parte incrível do artigo, na qual aparece apenas uma leitura sucinta de vários outros de seus artigos sobre o inconsciente. Por exemplo, quando afirma que "o núcleo do Ics consiste em representantes instintuais que procuram descarregar seu investimento; isto é, consiste em impulsos carregados de desejo" (FREUD, 1915c/ 1974, p.213), ou quando resume o trabalho do sonho, isto é, a ausência de negação, o deslocamento, a condensação, a atemporalidade, a submissão ao princípio do prazer, a substituição da realidade externa pela interna, todas estas afirmações datam de tempos passados, aparecendo pela primeira vez em 1901, em 'A interpretação dos sonhos'. Pode-se argumentar que o sonho não é o inconsciente. Mesmo assim, compartilham muitas feições, de acordo com as definições de cada uma delas por Freud. Aqui também se pode questionar a necessidade deste capítulo no artigo de 1915, do qual tratamos.

Ainda, depois de definir as características do Ics, Freud avança e estabelece também as principais feições do Pcs, de forma que as primeiras são definidas, definitivamente, por suas oposições às últimas. Freud reconhece isto de imediato, afirmando: “Só poderíamos apreciar a importância total das características do sistema Ics. acima descritas contrastando-as e comparando-as com as do sistema Pcs” (FREUD, 1915c/1974, p.215).

E continua, explicando em detalhes as principais características do Pcs: estabelecer a comunicação entre os conteúdos de representações de forma que possam influenciar um ao outro, organizar estes conteúdos temporalmente, introduzir a censura ou mesmo várias camadas de censura, instituir o teste de realidade e o princípio de realidade e, por fim, promover o desenvolvimento da memória como oposto a traços de memória, que pertencem unicamente à inscrição de experiências do inconsciente.

Este postulado sobre os traços de memória é bem curioso e pode nos levar a questionar algumas das afirmações de Freud em seu quinto capítulo, bem como a muitas formas tradicionais de abordar a metapsicologia, a psicanálise ou suas técnicas.

De fato, durante a discussão da relação entre os dois sistemas Ics e Pcs, o assunto do sexto capítulo de seu artigo, quando se empenha em estabelecer pontes entre eles e o consciente, bem como a hipótese de várias camadas da censura, 
Freud não hesita em apontar:

"Seria não obstante errôneo imaginar que o Ics permanece em repouso enquanto todo o trabalho da mente é realizado pelo Pcs - que o Ics é algo liquidado, um órgão vestigial, um resíduo do processo de desenvolvimento. Também é errôneo supor que a comunicação entre os dois sistemas se acha confinada ao ato de repressão, com o Pcs lançando tudo o que lhe parece perturbador no abismo do Ics. Pelo contrário, o Ics permanece vivo e capaz de desenvolvimento, mantendo grande número de outras relações com o Pcs, entre as quais de cooperação. Em suma, deve-se dizer que o Ics continua naquilo que conhecemos como derivados, que é acessível às impressões da vida, que influencia constantemente o Pcs, e que, por sua vez, está inclusive sujeito à influência do Pcs." (FREUD, 1915c/1974, p.218, grifo nosso)

Quando Freud afirma que a regra do princípio do prazer ou a substituição da realidade externa pela interna são características do inconsciente, parece esquecer a própria afirmação, de acordo com a qual, de forma abrangente, é a mesma 'realidade externa' que nutre a 'realidade interna' e, portanto, a distinção entre 'interna' e 'externa' merece ser renovada e estudada constantemente, começando com a precisa avaliação do que já tem sido feito de modo a dar uma idéia de como se tentou manter uma distinção impermeável entre esses dois domínios, de um lado, e como se tentou apontar a circulação e movimento ocorrendo entre eles. No primeiro caso, temos Ernst Jones ou Melanie Klein, com seus seguidores, no segundo caso, temos Lacan, mas também Lyotard e Deleuze, por exemplo.

Esta última concepção freudiana é constantemente afirmada: "Mas o Ics é também afetado por experiências oriundas da percepção externa. Normalmente, todos os caminhos, desde a percepção até o Ics, permanecem abertos e só os que partem do Ics estão sujeitos ao bloqueio pela repressão" (FREUD, 1915c/1974, p.222, grifo nosso).

Ao longo destas duas partes de seu artigo, exemplos clínicos trazidos por Freud mudaram de natureza. Não mais pertencem ao domínio da neurose, mas ao domínio do inconsciente e seus derivados, isto é, sonhos e fantasias, sintomas e patologia em geral, além de considerações acerca das técnicas psicanalíticas que o tornam inteiramente dependente do consciente.

O quinto capítulo termina, então: “Além disso, devemos estar preparados para encontrar nos seres humanos possíveis condições patológicas sob as quais os dois sistemas alteram, ou mesmo permutam, tanto seu conteúdo como suas características” (FREUD, 1915c/1974, p.217).

E, ao final do sexto capítulo, Freud escreve: "Uma completa divergência de suas tendências, uma total separação dos dois sistemas, é o que acima de tudo caracteriza um estado patológico" (FREUD, 1915c/1974, p.223). 
Desta forma, não é surpresa que o sétimo e último capítulos de seu artigo, intitulado 'Avaliação do inconsciente', seja inteiramente consagrado ao estudo e discussão da esquizofrenia, com base em casos clínicos e teorias trazidas por Victor Tausk que Freud torna seus. As propostas revolucionárias formuladas então podem ser resumidas: os esquizofrênicos encaram as palavras como se fossem coisas; em paralelo, desenvolvem ‘fala do órgão', de modo semelhante à hipocondria.

A importância de Tausk para a história da teoria analítica não deve ser negligenciada. Nunca é demais lembrar que o conceito de identificação projetiva nasce das idéias de Tausk elaboradas a partir de suas experiências clínicas e que os estudos de Bion sobre as formas esquizofrênicas de pensar e utilizar palavras também lhe são devidas. Mesmo assim, Freud aponta tanto as suas prioridades quanto a de seus seguidores mais próximos quando pensa ter encontrado nestas teses argumentos para solucionar o problema que formulou sobre a ‘dupla inscrição'. Afirma:

“Agora parece que sabemos qual a diferença entre uma representação consciente e uma inconsciente. As duas não são, como supúnhamos, registros diferentes do mesmo conteúdo em diferentes localidades psíquicas, nem tampouco diferentes estados funcionais de investimentos na mesma localidade; porém a apresentação consciente abrange a representação de coisa mais a representação de palavra ligada a ela, ao passo que a representação inconsciente é apenas a representação de coisa." (FREUD, 1915c/1974, p.229/230)

É surpreendente que Freud anuncie seu artigo sobre o inconsciente primeiramente a Lou Andréas-Salomé, e que depois termine o texto com uma longa consideração sobre as teses e a experiência clínica de Tausk. De fato, este jovem analista desfrutou de muitos favores junto a Lou-Andréas. O artigo de Freud parece provir de uma dupla transferência em relação a este casal, que tinham tido um affaire, o que marcou sua vida, um excluindo o outro em seus próprios pensamentos (GAY, 1991, p.220 e 448). O anúncio feito a Lou Andréas de um artigo sobre inconsciente que deveria conter uma nova definição do termo parece hoje em dia uma fanfarronada, com o objetivo de fazer a jovem interessar-se por ele e desinteressar-se de Tausk.

A posição de Freud em relação a seu jovem e brilhante discípulo, que fornece os dados clínicos e o primeiro esboço teórico para a abordagem freudiana das esquizofrenias, é bem mais complexa. O que Freud exprime em carta a Karl Abraham com data de 6 de julho de 1919 é, moralmente, abominável: "Embora suas qualidades bastante reais, ele não nos era de nenhuma utilidade”. ${ }^{6}$ Entretan-

\footnotetext{
${ }^{6}$ Esta carta foi suprimida na edição francesa da correspondência entre os dois psicanalistas. Mencionada por P. Gay, em Freud: une vie, Hachette, Paris, 1991, trad. T. Jolas, p. 449 e 797, ela foi
} 
to, é verdade que a linguagem política da Europa nesta época era em geral indecente e obscena. Em conversa íntima, Freud revela outros aspectos de sua maneira de ser. A Jekels, que lhe perguntava porque não analisar Tausk ele mesmo, Freud responde: “Ele acabará me matando.” (idem, p.798). Enfim, em carta a Lou Andréas-Salomé, Freud é mais delicado e parece trazer bastante nuances às suas apreciações sobre Tausk, enquanto Lou Andréas, ela, outrora tão apaixonada pelo “estudante de olhos verdes" e pelo "Vândalo de doce coração", prefere escolher a posição de menininha respeitosa do velho professor. O texto de 1915 parece marcado profundamente por todas estas contradições.

Assim como o próprio inconsciente, que obedece a processos primários e arcaicos, e provém de elementos excluídos da vida consciente ou incapaz de obter acesso a ela, seja porque são muito perigosos ou por parecerem inúteis.

Recebido em 9/3/2005. Aprovado em 18/4/2005.

\section{REFERÊNCIAS}

ANDREAS-SALOMÉ, L. (1912-13/1970) Correspondance avec Sigmund Freud, in Journal d'une année (1912-1913), Paris: Gallimard.

BLEULER, E. (1906) Ubewusstes und Assoziation, in JUNG, C.G. (ed.) Diagnostische Assoziationsstudien, Leipzig: Barth, p.7-145.

BRÈS, Y. (1985) Hartmann et l'inconscient romantique, in Critique des raisons psychanalytiques, Paris: PUF.

BREUER, J. \& FREUD, S. (1985[1893-95]) Studies on Hysteria. The standard edition of the complete psychological works of Sigmund Freud, London: The Hogarth Press, v. 2.

FREUD, S. (1975) The standard edition of the complete psychological works of Sigmund Freud, London: The Hogarth Press.

(1900-01) "The interpretation of dreams", v.4.

(1905) “Three essays on the theorie of sexuality", v.7.

(1911) "Psycho-analytic notes on an autobiographical account of a case of paranoia (Dementia Paranoides)", v. 12.

(1912a) “Contributions to discussion on masturbation”, v.12.

(1912b) “The dynamics of transference”, v.12.

(1912c) “A note on the Unconscious in psycho-analysis", v.12.

(1912d) "On the universal tendency to debasement in the sphere of love (Contributions to the Psychology of Love)", v.11.

incluída na nova tradução completa desta correspondência, graças aos cuidados de E. Falzeder. Cf. The Complete Correspondence of Sigmund Freud and Karl Abraham (1907-1925) (Ed.), Falzeder Ernst Editor, Karnack Bookshops, Londres, 2002. 
(1912e) "Recommendations to physicians practicing psycho-analysis", v. 12 .

(1912f) "Types of onset of neurosis", v.12.

(1913 [1912-13]) “Totem and Taboo", v.13.

(1915a) "Papers on Metapsychology”, v. 14.

(1915b) "Repression”, v.14.

(1915c) “The Unconscious”, v.14.

(1950 [1895]) "Project for scientific psychology", v.1.

. (1974) Edição standard brasileira das obras psicológicas completas de Sigmund

Freud, Rio de Janeiro: Imago.

(1893-1895) "Estudos sobre a histeria", v.2.

(1897) “Carta de 24 de janeiro”, v.1.

(1905) "Três ensaios sobre a teoria da sexualidade", v.7.

(1915b) “Repressão”, v.14.

(1915c) “O inconsciente”, v.14.

. \& ABRAHAM, K. (2002 [1907-25]) Correspondance. London:

Karnac.

\& FLIESS, W. (1981 [1887-1904]) The Complete Letters. Belknap \& Harvard.

GAY, P. (1991) Freud, une vie. Paris: Hachette.

HARTMANN, E. von (1994 [1869]) Philosophie des Unbewussten. Versuch einer Weltanschauuung. Berlin: Carl Duncker.

(1967 [1909]) A General Presentation on Freud's Theorie (Propaganda Among Physicians), in NUNBERG, H. e FEDERN, E. (eds.), Minutes of Vienna Psychoanalytic Society, 21 April 1909, International University Press.

MASON, J. M. (1985) The Complete Letters of Sigmund Freud toWilhelm Fliess 18871904. Cambridge, Massachusetts and London, England: The Belknap Press of Harvard University Press.

NUNBERG, H. \& FEDERN, E. (eds.) (1908-10) Minutes ofVienna Psychoanalytic Society, v. II, trans. by M Nunberg. New York: International University Press, Inc.

PRADO DE OLIVEIRA, L.E. (1998) Sublimation et symbolization: retrouvaille et fêtes, in EIGUER, A., LEPRINCE, C., BARUCH, F. La fête de famille, Paris: In Press Editions.

— (2005) The Unconscious, in PERELBERG, R. Freud for a modern, London: Whurl Books.

PFEIFFER, E. (ed.) (1972) Sigmund Freud and Lou Andreas-Salomé letters. London: Hogarth Press.

WHYTE, L. L. (1974) The unconscious in history. Contemp. Psychoanal. 10: 379-85.

Luiz Eduardo Prado de Oliveira

prado.de.oliveira@wanadoo.fr 